Essigsäure und Ferrocyankalium versetzte Probe mit dem filtrirten Harne zu vergleichen; eine Zunahme der Trübung im ersten Falle zeigt die Anwesenheit von Eiweissspuren im Harne an. Diese zum Nachweise geringer Albumen-Spuren nothwendige Manipulation lässt sich gar nicht oder nur schwer mit Bakterienharnen anstellen, indem dieselben durch ein gewöhnliches Filter, dessen Maschen und Lücken gross genug sind, um die Schyzomyceten durchzulassen, vollständig trübe durchgehen. Wir empfehlen daher zu diesem Zwecke den Harn mit Kieseiguhr zu schütteln und zu filtriren, wobei ein klares Filtrat erhalten wird. Allerdings hat man bei diesem Verfahren zu berücksichtigen, dass durch Schütteln schleimigeitriger Harne, welche reich an Leukocyten sind, mit Kieselguhr, Spuren von Albumen auf dem Niederschlage haften bleiben. In diesem Falle genügt es aber den Niederschlag mit warmer Kalilauge auszuwaschen, das Filtrat mit Essigsäure im Ueberschuss zu versetzen und die Probe in oben angegebener Weise auszuführen. Man kann auf diese Weise die geringsten Eiweissmengen in Bakterienharnen nachweisen.

Ueber den Nachweis fremder Rohphosphate im Thomasschlackenmehl. Von

\title{
L. Blum.
}

Die Ueberlegenheit der Thomasschlacke gegenüber den anderen Rohphosphaten wird wegen ihrer leichten Assimilirbarkeit allseitig anerkannt, wofür als sprechendster Beweis die hohe Preissteigerung gelten kann, welche dieselbe in letzter Zeit im Handel erfahren hat. Mit dieser Preissteigerung der Thomasschlacke macht sich eine grosse Flauheit in den Preisen des natürlich vorkommenden Phosphats fühlbar. So notirte z. B. in Lille den 10. Mai graue Phosphatkreide von Mons, fein gemahlen,. mit $40-45 \%$ Calciumphosphat $\dot{0}, 53$ Franes pro Einheit Calciumphosphat pro Tonne, was einem Preise von 0,11 Francs für das Kilogramm Phosphorsäure entspricht. Man hat deshalb mit der Möglichkeit za rechnen, dass diese billigen, fein gemahlenen Rohphosphate entweder für sich allein als Thomasschlackenmehl in den Handel gebracht oder dem Thomasschlackenmehl zugesetzt werden können, um so mehr noch, da dieselben dáza geeignet wären, den Phosphorsäuregehalt eines geringwerthigen Schlackenmehles auf unlautere Weise anzureichern. 
Die Frage, ob anstatt der Thomasschlacke auch Phosphatmehl oder ähnliche Rohphosphate mit gleichem Vortheil zu Düngungszwecken zu verwenden wären, ist in jüngster Zeit vielfach besprochen worden. Dieso Meinung ward durch die Arbeiten P. Wagner's and verschiedener anderer Forscher als eine irrthümliche erkannt, indem durch dieselbe nachgewiesen wurde, dass es selbst durch die feinste Mahlung nicht möglich sei, ein jedes unaufgeschlossene Phosphat in ein genügend wirksames Düngemittel zu verwandeln. Ein Zusatz davon zu Thomasmehl schliesst deshalb immer eine Benachtheiligung des Käufers ein, und an den Chemiker tritt die Frage heran: Wie lässt sich auf analytischem Wege die Gegenwart von fremden Rohphosphaten im Thomasschlackenmehl leicht nachweisen?

Die jetzt übliche Bestimmung der Phosphorsäure - Auflösen der Substanz in Mineralsäuren und Fällen als Ammoniumphosphordodekamolybdat oder direct in alkalischer Lösung als Magnesiumammoniumphosphat - schliesst diesen Nachweis aus. Man wäre also genöthigt, auch für die Thomasschlacke die Citratmethode einzuführen, um eine richtige Werthbestimmung derselben zu erzielen.

Vergleicht man hingegen die Gesammtzusammensetzung der Thomasschlacke mit derjenigen der Rohphosphate, so lassen sich gleich Schlüsse ziehen, welche die Gegenwart der letzteren im Thomasschlackenmehl vermuthen lassen. Es sei hierbei bemerkt, dass dazu nur diejenigen Rohphosphate verwandt werden können, welche, neben einem niedrigen Phosphorsäuregehalte gegenüber einem hohen Gehalte an Schwefelsäure verbrauchenden Substanzen - besonders Calciumcarbonat - eine lohnende Verarbeitung auf Superphosphat nicht mehr zulassen. Für hochgradige Phosphate zahlt die Superphosphatindustrie einen zu hohen Preis für das Kilogramm Phosphorsäure, so dass für den Fälscher kein Vortheil mehr in deren Anwendung bestehen würde.

Nehmen wir z. B. die oben erwähnte graue Phosphatkreide von Mons. Sie enthält: $40-55 \%$ Calciumphosphat bei etwa $50 \%$ Calciumcarbonat; also etwa 22\% Kohlensäure, wenig Eisen und kein Mangan oder nur Spuren davon. Die frische reine Thomasschlacke hingegen enthält keine Kohlensäure neben oft bedeutenden Mengen Eisen und Mangan.

Findet nun eine Versetzung von Thomasschlackenmehl mit dieser gemahlenen Phosphatkreide statt, so resultirt daraus eine Mischung, welche, je nach der Menge des Zusatzes, einen hohen Gehalt an Kohlen- 
sänre enthalten kann. Ausserdem verringert sich der Eisen- und Mangangehalt derselben. Wir hätten also in dem Vorhandensein von Kohlensäure in einem Thomasmehl einen Anhaltspunkt, um auf die Gegenwart fremder Beimengungen zu schliessen, weil die Darstellung der Thomasschlacke auf den Stahlwerken einen Gehalt an Kohlensäure vollständig ausschliesst. Gegen diese Darstellung lässt sich jedoch einwenden, dass die Thomasschlacke freien Kalk enthält, welcher begierig Kohlensäure aus der Luft absorbirt, und dass mithin ein etwas gelagertes Thomasmehl einen gewissen Gehalt an letzterer enthalten muss. Auch ist es nicht unwahrscheinlich, dass das in der Thomasschlacke enthaltęne Tetracalciumphosphat durch die Kohlensäure der Luft unter Bildung von Calciumearbonat zerlegt wird. Der Einwand ist begründet, und ich habe mir durch folgende Versuche Aufklärung darüber zu verschaffen gesucht. Ich bestimmte die Kohlensäure in verschiedenen Proben, welche mir zu Gebote standen. Da in den Schlacken durch Säuren zersetzbare Schwefelverbindungen vorhanden sind (CaS. MnS), so gebrauchte ich zur Ausführung der Bestimmung den Apparat, welcher gewöhnlich zur Verbrennung des Kohlenstoffs vermittelst Chromsäure und Schwefelsäure angewandt wird. Zur Zersetzung diente gleichfalls ein Gemisch beider Säuren, so dass ich sicher war, keine Schwefelverbindungen in den Absorptionsapparat zu bekommen. Die auf diese Weise erhaltenen Gehalte an Kohlensäure waren folgende:

1) Frische ungemahlene Thomasschlacke in Stücken . . 0,00\%

2) Probe von im Handel vorkommender Thomasschlacke, fein gemahlen . . . . . . . . . . . . . Spur*)

3) Andere Probe vorkommender Thomasschlacke, fein gemahlen . . . . . . . . . . . . . . . $0,16 \% *)$

4) Verwitterte Thomasschlacke, welche drei Jahre lang an der freien Luft gelegen hatte, feines Mehl . . . 2,28\%

5) Dieselbe; gröberes Mehl . . . . . . . . . 2,18\%

6) Dieselbe; die zur Kohlensäurebestimmung dienende Probe wurde im Achatmörser fein gerieben und blieb 8 Tage lang, auf einem Stück Papier dünn ausgebreitet, der Einwirkung der Laboratoriumsatmosphäre ausgesetzt . . . . . . . . . . . . . . $2,47 \%$

*) H. Ot to (Chemiker-Zeitung 11, 255 [1887]) fand bei einer Analyse von Thomasschlacke, welche er dort mittheilt, ebenfalls nur eine Spur Kohlensäure. 
Die zu Versuch 6 dienende Probe ergab einen Glühverlust von $2,87 \%$. Das Plus von $0,40 \%$ rührt von Feuchtigkeit und Hydratwasser her. Man kann für diesen Fall deshalb mit Bestimmtheit annehmen, dass die gefundenen $2,47 \%$ der Maximalgehalt an Kohlensäure ist, welchen die betreffende Thomasschlacke aufzunehmen vermag. Dieser Maximalgehalt kann nun allerdings, je nach der anderweitigen Zusammensetzung der Schlacke für jeden besonderen Fall variiren.

Veranlassung zu dieser Mitheilung gab mir die Analyse eines Thomasschlackenmehles, welches neben dem ausbedungenen Phosphorsäuregehalte $10,3 \%$ Kohlensäure enthielt. Es war für mich zweifellos, dass dasselbe mit einem minderwerthigen, gemahlenen, natürlichen Rohphosphate verfälscht war, welches einen hohen Gehalt an Calciumcarbonat hatte.

Obgleich sich nun durch die Bestimmung der Kohlensäure die Gegenwart anderer Rohphosphate nicht direct nachweisen lässt, so bietet sie doch ein geeignetes Mittel, um mit leichter Mühe entscheiden zu können, $o b$ ein Thomasschlackenmehl in dem erwähnten Sinne za beanstanden ist oder nicht. Dazu genügt eine einfache Bestimmung des Glühverlustes der getrockneten Substanz; fällt dieselbe zu hoch aus, dann ist die Authenticität der Probe als reines Schlackenmehl in Zweifel zu ziehen, und man hat Ursache, weitere Untersuchungen damit anzustellen.

Diese Mittheilung gibt den Fachgenossen vielleicht Anregung zur Festsetzung einer bestimmten Norm, über welche hinaus der Kohlensäuregehalt, respective der Glühverlust, eines Thomasschlackenmehls nicht hinausgehen darf. Es ist übrigens anzunehmen, dass derselbe bei handelsüblicher Waare bedeutend geringer ist, als die Zahlen, welche ich bei meinen Versuchen 4,5 und 6 erhalten habe.

Esch a. d. Elz, den 22. Mai 1890.

\section{Zur Bestimmung des Schwefels in anorganisehen Sulfiden.}

(Briefliche Mittheilung.)

Von

r. Blum.

Ich erlaube mir die Freiheit, Sie auf folgende Prioritätsberichtigung aufmerksam zu machen:

In einem Referat über die Sitzung vom 16. Mai der chemischen Gesellschaft zu Heidelberg bringt die »Chemiker-Zeitung « (1890, 14, 